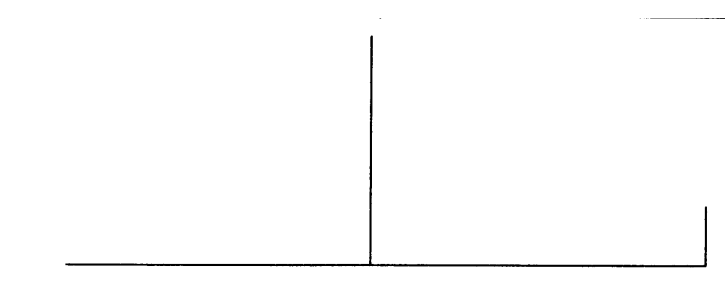

\title{
Os "amores" na clínica: uma investigação psicanalítica
}

\author{
Aluísio Pereira de Menezes
}

O trabalho procura pôr em questão certas dificuldades contidas no uso não-refletido do termo "amor" em psicanálise. Partindo da identificação de semânticas que caracterizam os significados da palavra "amor", pergunta-se: "São estes significados que compõem e norteam as coordenadas do entendimento psicanalítico?". O que se procura mostrar é como a aceitação da hipótese de inconsciente determinaria o eixo semântico e conceitual com que se aborda tudo o que se designa como "amor".

De forma bem sintética, o autor examina que fatores caracterizariam o determinismo do amar e dos amores. Traça um quadro onde é possível situar como o pensamento psicanalítico entende a origem de muitos sofrimentos deles decorrentes. Retoma e reconsidera a enorme importância de conceber-se o encontro de "amor". Desse modo, o trabalho é um roteiro articulado para que se perceba: 1) a necessidade de repensar as implicações do sentido das transferências e dos amores na clínica psicanalítica; 2) a natureza dos fenômenos amatórios em função de aceitar-se a hipótese de um inconsciente. A pergunta que ficaria no ar pode ser formulada assim: "Em que medida todos os amores se comportariam tal como previsto pelas metapsicologias mais dominantes no campo psicanalítico?". 


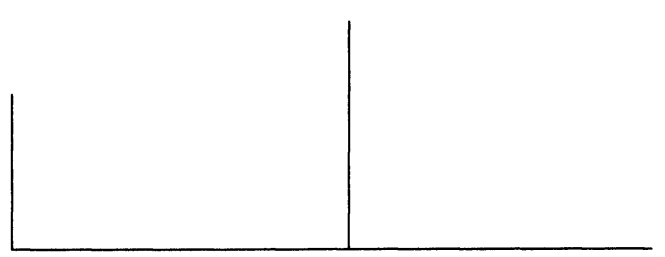

I

São vários os significados do termo AMOR na tradição cultural do Ocidente. Nosso problema aqui, no entanto, é ressaltar o delimitado discernimento posto pela atividade clínica a respeito das manifestações de "amor". Ele será colocado entre aspas até o momento em que pudermos conceituar o que seja o amor para a psicanálise, nas condições atuais.

Como a psicanálise lida com o "amor" nessa pluralidade de significados? Vale dizer: como a psicanálise lida com manifestações discursivas referidas ao "amor", ou seja, como ela lida com aquilo que acabou empacando, num determinado momento da vida, seja por causas abruptas ou cumulativas, "internas" ou "externas", assumindo a proporção problemática justamente nas manifestações do dito "amor", por vezes comprometendo até o próprio sentido que comanda as ações na configuração modal de cada vida, quase inapelavelmente instada diante do semelhante.

A psicanálise lida com isso que acabou fracassando, de algum modo, em operar uma resolução de si com a própria gênese, com o estado de desamparo ou os diversos estados de solidão e de privação, antes e depois, do ser bebê, do ser criança, com os respectivos continentes semânticos que nos fizeram existir (ao que busca tratamento e a nós que o ofertamos) e nos impuseram sua valoração prioritária de referência e suas implicações superegóicas, mas sobretudo com isso que sempre está envolvido se admitirmos o inconsciente, isto é, com a inóspita deriva pulsional, o quinhão de cada um em relação aos aparelhos sensíveis, aos impulsos e às intensidades. $E$ isso tudo tem uma marca específica de delimitação: a admissão de uma sexualidade inconsciente operando por trás das ações que insistem e causam sofrimento. Sem a hipótese de um "inconsciente" onde ficaria ancorada a psicanálise? Como ela situaria e pensaria o "amor" sem levar isso em conta?

Assim sendo, de dentro de uma sociedade onde progressivamente se foi desenraizando dos mitos e das fábulas morais que encarnavam a diversidade do que seria exemplar ou não, no jogo da gênese e do desenvolvimento do psiquismo frente à sua história (sua família, sua 


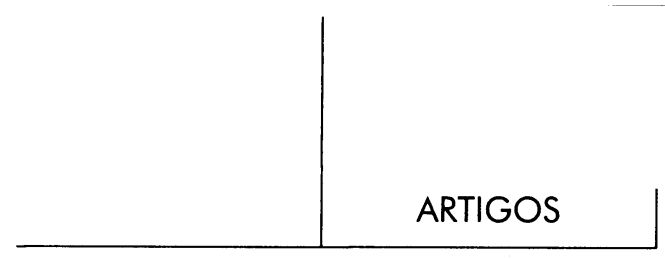

cultura, seus valores), na busca de dar um sentido específico à existência através de algo que ponha uma "verdade" no vínculo com um ser determinado, é comum o fracasso; são os desastres de "amor" que aí falam, que vêm buscar ajuda (não propriamente procurar uma análise), quando consegue se dar conta de que algo não funciona mais. E, em algum grau, há um pedido de socorro, explícito ou velado. É preciso ter claro, aí, que essa exigência não está mais referida apenas ao propósito de unir, de acoplar, de socializar. Essa verdade não está mais só referida à base biológica do "amor". Essa semântica certamente informa a maior parte das concepções. E não esqueçamos que é aí o ponto que precisamos indagar: a psicanálise certamente aceita a base biológica (pelo menos Freud), a questão é saber se a clínica revela um outro horizonte que faça consistir uma definição um pouco diversa porque incluiria a possibilidade de que o inconsciente seja no fundo mais do que uma elucubração dos processos e dos mecanismos biológicos.

Algo se busca no "amor"; parece que aquilo tem pega muito antiga. A exclusividade do objeto revela o quanto aquilo é semelhante a algo criado com emoções, sentimentos e "afetos" (precisamos conceituar afeto) e que pesou no íntimo reconhecível como si e para si em função do outro mais arcaico e suas diversas funções. Tem-se aí um misto: uma base biológica (etológica) + uma memória, digamos, "afetiva". Indo bem rápido, coloquemo-nos na perspectiva de uma clínica na qual uma idéia de "amor" esteja presente nas manifestações sintomáticas. Isso não delimita toda a clínica, apenas indica um tormento modulado por entidades clínicas. Peguemos o que torna, ou o que quer fazer acreditar ser, o "amor" - o "objeto do amor" - coisa única (houve algum "encaixe", mas será o mesmo que o biológico?). A pergunta "O que tem valor soberano, que é de todos diferente, dentre um conjunto extenso de elementos?" carregará enorme ambigüidade tanto se lançada no campo das manifestações ocidentais do "amor", quanto se for no das manifestações religiosas, ocidentais ou não. O que se espera conseguir no "amor"? O que se espera nos atos de crença, ou mesmo nos de fé? O sagrado não é o valor supremo? Com certeza muitas "concepções de amor" têm afinidade com a dimensão religiosa, ou é o contrário? O religioso comporta algo além da semântica trazida pela ordem do vivo? O que nos interessa, neste momento, é apenas destacar a pluralidade e a profundidade de modos que operaram na evolução e informaram a linguagem de pensar e de viver que antecedem, e de muito, o próprio advento da psicanálise. Se considerarmos que, além do sagrado, num outro pólo, temos o sexo, o sexo antes da psicanálise, a imensa cultura do sexo, veremos que o fenômeno do "amor" tanto se manisfesta por si, como também serviu de referência metafórica para inteligir certas experiências religiosas, onde, às vezes, até não há necessária contradição ao unir sexo e sagrado. 


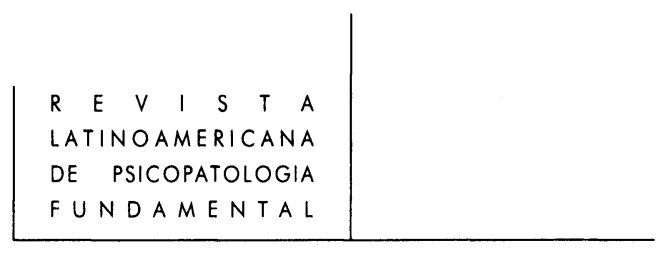

Há uma enorme cultura de "concepções de amor". Há a memória de um elenco de realizações prático-discursivas encarnando, traduzindo concepções de "processos amorosos". Há uma massa de estudos e de textos interpretativos, sob ângulos e saberes diversos. Há romances e poemas. Há mitos e lendas. Há arte de verdade trazendo a "cena de amor". Até onde vai o fenômeno do amor? Até onde, de dentro desta cultura em que estamos, podemos falar e tratar do "amor" de uma forma pertinente, com outro peso que o de ser algo fundamental desde o biológico e seu "amor" pela insistência em ser? Será um hábito da espécie humana o amar? O fato é que há, seguramente, uma enorme massa de sofrimento amoroso. Mas nenhum amor é só sofrimento. Entre o que se diz afetado e as motivações de mexer ou não (mas será uma escolha?) com a situação de viver um amor, existem muitas posições, doentias ou não, mas nada indica que sejam infinitas, ou, então, que se distinga do enciclopédico. Por sua vez, isso não deixa de evidenciar quão parca é a exploração da experiência amorosa, experimentalmente falando. Detém-se no sofrimento, apura-se o superar ou o transformar ou o variar o sofrimento, raramente se sai do já contado. Uma certa paciência destaca isso.

Como, de dentro das reedições amorosas ao longo de um curso de vida, $o$ que comanda o conjunto dos movimentos, que leva ao sofrer, ao pedido de ajuda e à tentativa de entender o que se passa, consegue ser articulado e tratado pela psicanálise ampliando o alcance da questão amorosa ao colocá-la, de forma determinada, mas intrínseca, no centro de sua própria chance técnica e verdadeira de intervenção através da transferência? Se há um outro eixo no amor que o de base biológica, sua dinâmica se esgotaria nessas formas aprontadas, como que reeditadas de um conjunto limitado, porém de larga tradição? A "base" psicocultural do "amor" seria o outro pólo exclusivo além do plano biológico? Os dois fatores situariam o alfa e ômega das manifestações do "amor"? A questão do "amor" coloca enormes dificuldades quando lidamos com o fenômeno em aberto, experimental, nas suas chances de formas novas, pela fonte que é o encontro raro e seus efeitos. Como se entender com isso? Em que medida o que aí se passa será integrável de fato na motivação biológica ou cultural? O certo é que existe um conjunto de indicadores razoavelmente conhecidos e que tornam os entendimentos psicanalíticos bem plausíveis quando a coisa remete ao antigo, a um antes que informaria o porquê dos "sofrimentos de amor". Mas o "amor" tratável só vai até aí? É preciso insistir nisso. Será assim? Todo o "amor" deriva da relação mãe-bebê, em última instância? A contribuição da psicanálise teria sido a de trazer apenas um esclarecimento ao mais antigo (sua idéia de inconsciente incestuoso) e ter posto o artifício da transferência como forma de trazer à fala e à ação o que precisava ser visto e dito para desvendar um ponto cego e paralisante? 


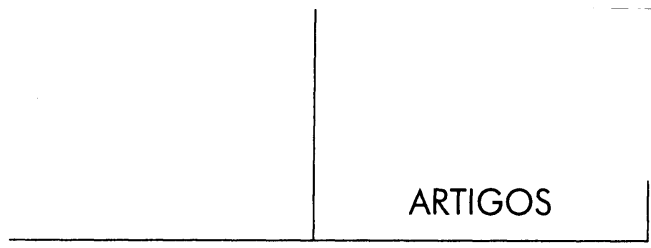

E se lidamos com "amores" não afeitos à reintegração a um mais antigo como bitola? Isso faz aparição, obriga uma escuta. Isso conduz a novas hipóteses sobre a experiência amatória, e, ato contínuo, à reconsideração do Ics que precisa acolher outro modo que a referenciação por matriz. E certamente essa forma de conceber implica em dizer que o amor pode estar referido a uma matriz, mas que pode também ser de outra maneira. Nem tudo é matricial. E nem será tampouco patricial necessariamente. Tentando sair desse Ics no limite quase etológico, para resguardar o incôngruo das estranhezas, muitas vezes caímos numa base diferente, mais porosa, é verdade, significante, embora reproduzindo o mesmo esquema de nucleação forte como jeito de determinação. Em virtude dos sofrimentos amorosos comparecem tanto sintomáticas sedimentadas na estratificação destes enredos quanto daquelas que decorrem de terem sido expostas a riscos, certamente que estas são bem mais raras. Quem terá provas em contrário? Ou não há "amor" além da conformação biológica-incestuosa definida pela relação matriz?

\section{II}

Existe, então, um plano no qual a análise lida com as conseqüências das peripécias ou mesmo de experiências "amorosas" no sentido mais imediato das manifestações de "amor" dentro de um processo societário e de um determinado regime moral e cultural. Por que as histórias de "amor" são muito convergentes e permitem a percepção de certas disposições típicas? Certamente porque a referência a certos modelos possui maior apreço identificatório e também porque certas passagens são obrigatórias, pelo longo período de dependência da espécie humana. A criança terá de passar por uma sucessão de etapas demarcadas. Não se pode esquecer que o "amor" de cuidados se encarna com a face de indução pedagógica. A contraface, o dom, é a instrumentação para enfrentar o desamparo, a privação, a solidão. $O$ fato de essa regra ser obedecida no seu caráter geral pelo princípio de realidade cultivado pela cultura da maternagem dos bebês não impede a existência de outras vizinhanças. Mas a vida é mais larga do que aprender a ter condições de ir levando a vida, de deixar de ser bebê ou criança. Mas sempre distinguindo a presença pulsante do bebê ou da criança favorecida por cuidados daquilo traz o caráter resultante da educação. A questão do "amor" está comprometida intrinsecamente com o sentido do que é viver, tanto no sentido de ir levando, quanto no sentido exploratório que se abre, por exemplo, quando a psicanálise põe para funcionar o expediente transferencial, o amor de artifício.

Por isso mesmo, num outro plano, de "amores" o analista tem de saber um pouco porque sua posição é no mínimo reflexa, já que o manejo da transferência implica o uso de uma forma "artificial", cabível nas tradições semânticas do 


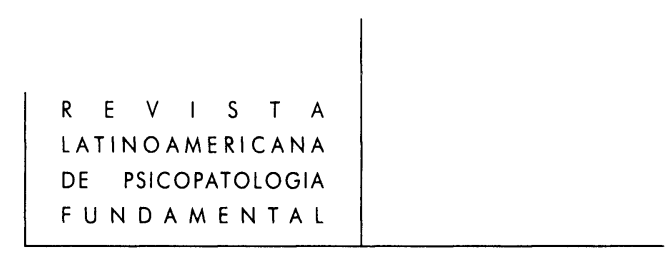

"amor" e das "iniciações" (fala-se de "amor de transferência"), que tem função nitidamente operatória, o que não exclui certos momentos autênticos (o que não significa que o operatório não o seja). Contudo, ficam sob suspeita as analogias sem investigação do que significa tratar do amar levando em conta a hipótese do Ics. Só aí poderemos dizer em que a experiência da transferência não é uma reedição de uma forma amatória arrolada na enciclopédia biocultural.

Esta reflexividade técnica do processo da análise coloca o analista na condição de um grau menor de cegueira no tocante às seduções do amor, um pouco mais desenvolto em relação a elas. No que se maneja a transferência isso está suposto. Isso significa dizer: nos limites possíveis da contratransferência, é claro. Freud deixa claro que os cuidados de negociação com os costumes não deve se sobrepor à verdade do que está em jogo, sendo dado que há motivações inconscientes.

O que se destaca aí é que se pode chegar à análise por um problema de "amor", mas, uma vez em análise, na transferência, o processo envolve também lidar com o artifício de um "amor". De uma forma, ou de outra, a psicanálise está envolvida com o "amor". Haverá alguma coisa sintomática - que leve à cena analítica - que não provenha do "amor"? Claro que sim. O famoso "amor de transferência" não nega que o que leva à análise possa vir de outra "afetação". Não é necessariamente um defeito. Nem todo sofrimento decorre de algo que "passa" pelo "amor". Admitamos que seja sustentável (o fato de discernir isso na clínica não é garantia) distinguir sintomas em função de o "amor", tomado de forma geral, vir a ser causa ou não. Em outras palavras: precisamos entender o que é o amor no interior do exercício da clínica, que conceitos o faz existir assim delimitado, que acontecimentos obrigam à suspensão da idéia de cura nucleada por uma resolução do recalcado ou pela capacidade de suspender o automático do imaginário. Amar direito não deixa de ser um tipo de medida, ainda que não se diga a coisa assim. O que significa estar curado desses "amores", inclusive deste provocado pela cena analítica? Ou estar curado seria acabar de amar já que o "amor" não tem o além da sua patologia? Mas na condição clínica, a perspectiva não é a de compatibilizar o processo da análise com algo como uma essência, ainda que de uma antropologia bem feita e fundamentada.

Ora, se isso for aceito, coloquemos um outro ponto. Não queremos mais destacar, introdutoriamente, a relação geral da psicanálise com as manifestações de "amor", mas chamar atenção para algo. Exigindo um pouco mais, tentemos destacar o que informa para a psicanálise a semântica menos ingênua que emprega, já que, no mínimo, ela não pode confundir o plano técnico com a manifestação (mesmo que se diversifiquem as formas de como "os amores de transferência" apareçam ali também na sua espontaneidade).

Retomemos algumas coisas, para dizer com clareza qual é a semântica básica que informa a quase totalidade do que conta como tradição psicanalítica ao 


\section{ARTIGOS}

considerar o "amor" na sua clínica e no seu pensamento. Assim definido esse quadro geral, consideremos que as manifestações de "amor" que levam à busca de algum tratamento psíquico procuram ser desvendadas pela psicanálise ("Só pretende descobrir nexos reconduzindo o manifesto ao oculto"), admitindo-se que existe uma motivação inconsciente por trás dessas expressões. O oculto aí no amor, na perspectiva inconsciente, é que os comportamentos amorosos e os seus respectivos sofrimentos, alegrias, desastres etc. podem ser entendidos e explicados na aceitação de que aquele sofrer - a manifestação que sofre e pede ajuda - tem uma explicação se levarmos em conta que a história de amor - os efeitos patológicos do estado amoroso - remete, no fundo, à matriz libidinal mãebebê. Digamos melhor: o patológico em causa pode ser abordado com a lente psicanalítica, o que significa dizer que o "amor" tem uma gênese e um desenvolvimento referidos à relação matricial. Biológico sim, mas já pulsional no sentido de "quantum de afeto".

O que fica por trás de todo amor, de todo patológico do amor, está referido ao que decorre de traumático na matriz como base fantasística inconsciente. Há o "amor narcísico": o amar-se através de. E isso é fantasia. Há o "amor siderado pelo outro": amar o diverso. Ora, o diverso é sempre outro em relação a si. E também aí temos o moto da fantasia. Para ir rápido, digamos que o incestuoso - ou seja, aquilo de que se tem de abrir mão porque não pode - fica indicado por fixações recalcadas relativas ao matricial. No que a pulsão está atrelada irremediavelmente à vida, estes processos mais arcaicos do fantasiar psíquico ficam marcados pela relação mãe-bebê, a tal ponto que o arcaico, o pulsional arcaico, só seja pensável em função do etológico-libidinal dessa relação matricial, ou, então, em função da relação patricial, seja ela edípica ou não. Uma enorme tradição psicanalítica tem na nucleação pós-natal e no seu caminhar edípico o referencial maior de onde surge o caráter problemático de inúmeras patologias envolvendo o "amor" (desde Freud). O que a psicanálise vem ensinando? Que as condições do amor estão bem plantadas nas relações incestuosas psíquicas que resultaram como obra do bebê desde que ele começou a se sentir bem ou mal no mamar etc. Essa é a situação padrão. O que a psicanálise ensina é que os problemas de "amor" trazem à cena, em última instância, dificuldades incestuosas, ou seja, dificuldades onde se ignora que o drama amoroso de agora está relacionado a uma fixação num passado arcaico dos modos de funcionar o psiquismo antes ainda da conquista da língua. O objeto de amor decorre de uma trama onde os fantasmas incestuosos estariam presentes e seriam referidos, repetimos, aos diversos avatares do par mãe-bebê. Afirmando-se ou negandose, tem-se aí o estofo presente à captura amorosa.

O que presidiria o encontro que normalmente convoca a palavra "amor" para nomear aquilo que é sentido como trazendo excepcionalidade? Não se esquecendo 


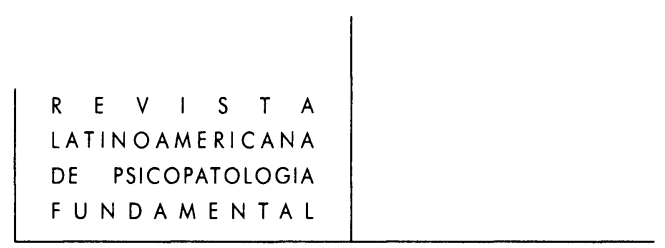

que excepcionalidade depende sempre das sensações e afetos que comandam o trabalho de dar sentido à vida, é necessário dimensionar quando e qual o acaso que entra em cena. O que se "encontra" no encontro de amor? Aquilo que fora, aquilo que será? Futuro anterior? Ou será outra coisa? Serão os mesmos acasos? Mas é o acaso dos processos biológicos que comanda? Disposição e encontro, em grego, lembra Freud, referindo-se ao que determina o destino de um ser humano, e acrescenta: "rara vez, talvez nunca, isso é feito por um só desses fatores". "Daimon" e "Tiquê". Os encontros decisivos para a composição de um destino se restringiriam ao que se passa entre mãe e bebê ou na triangulação edípica? A disposição de si do organismo acoplado ao regime materno esgotaria a ordem de acontecimentos que repercutiriam ao longo da vida, seja ela doente ou não? Por isso é preciso saber se o "encontro amoroso" sustentado pela psicanálise decorre da mesma semântica biológica ou se esgota num matricial (materno, paterno ou misto). E a seguir perguntar se o pré-edípico e o edípico seriam a semântica máxima a respeito do que se designa como o estofo do "amor". Por isso é crucial perguntar até onde vai o estranho, a excepcionalidade, se eles vão logicamente diferente do que se faz etológico. Senão é o caso de anular sua pertinência, já que é a condição do humano biológico que, em última instância, comanda.

Para uma excelente concepção biológica do encontro, ler "Reflexões sobre o amor" de Humberto Maturana. Como não posso me estender aqui, digo que o crucial para a psicanálise na questão do "amor" é a de lidar com a especificidade do que seja o inconsciente e seus modos de manifestação. Para se ter uma perspectiva bem rigorosa do problema, seria importante entendermos o que Boris Cyrulnik nos diz sobre "biologia periférica". Onde se ancorariam os fenômenos incestuosos fora dessa periferia do outro? Todo "amor" sidera em torno de um outro? Mas que tipo de "amor" é siderar em torno de um objeto? Ou será isso o desejo manifestando-se como paixão? O encontro cum um traço (objeto de desejo travestido de objeto de "amor") coloca um reencontro com um suposto objeto matricial que configura a disposição que antecede ao encontro.

\section{III}

Lacan certamente contribuiu para se pensarem as paragens máximas das experiências envolvidas no amar, e sobretudo a natureza dos fracassos amorosos. Chegou mesmo a considerar que a psicanálise não podia ser uma ciência porque era impossível conceber o que se faz na análise fora de um plano onde o amor não fosse fundamental.

Centrando a clínica como experiência do sentido, indicando os seus limites, pela própria natureza sexual do falante e sua pertença inapagável à falha na linguagem, ele modula todo o processo pulsional pelo regime do desejo em torno 


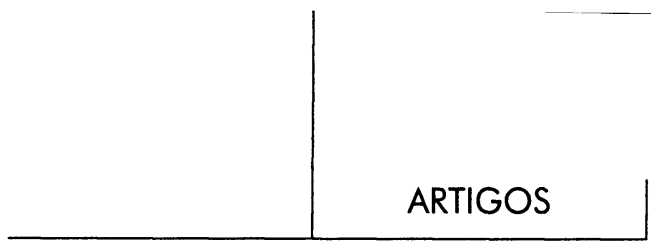

de um objeto, a máquina lógica e imperativa de sua composição estrutural, com isso fazendo a cena do homem e da mulher em suas fórmulas quânticas espelhar a atração irresistível incluindo a impossibilidade da junção, a tal ponto que essa distância colocada estampa a sorte do que no amor se evidenciaria como o impossível absoluto do incestuoso e sua única chance de saída sendo a "lettre d'âmour" ("carta de amor"). Só não é tão evidente que tudo se reduza à conclusão de que, sendo dada a estritíssima dependência ao Outro (Autre), o amor seja impossível, e a única chance de algum gozo, no amar, é falar do fracasso de amor, sua impossibilidade.

O amor é impossível porque é amor de morte, a fixação ao incestuoso defunto, a carniça que não se quer largar. "Não é dado ao [sujeito] atingir seu parceiro sexual, que é o Outro, senão por intermédio disso que é a causa de seu desejo", diz Lacan na página 75 do Encore. A causa do desejo é informada por essa dependência ao Outro parceiro. Já vimos que há duas versões mínimas dessa dependência: uma matricial materna, etológica, e outra, paterna, cultural. Duas formas de nucleação identificatória. Entre a perspectiva mais etológica da psicanálise (relação matricial mãe-bebê) e a versão mais lógica da psicanálise (relação patricial Outro-sujeito), existe pelo menos um aspecto que precisa ser sublinhado, e que o simples fato de estarmos de acordo quanto ao caráter fantasístico, não resolve muita coisa. Será preciso discernir se a tradução das pulsões em seu destino obedece ao ponto central de referência, seja de domínio biológico, em última instância, seja de domínio simbólico (o inconsciente seria estruturado como uma linguagem), numa outra tese de ponto irredutível. Uma vez posta uma nucleação forte, a pulsão fica atrelada à expressão das emoções e a toda sua cultura, ou, então, ao "Outro que segura as cordinhas" do assujeitamento.

Mas o etológico não é tão imaginário quanto se quis fazer crer. Há fazer análise onde o inconsciente apareça pelo traumático pré-edípico ou edípico, com maior peso num incestuoso cego cujo estofo remete aos processos de contato com a presença ou não do corpo da mãe, seus traços, e com tudo aquilo que habita aquela "subjetividade". Ou há fazer análise onde o inconsciente faça seu vagido num enraizamento simbólico, um trauma lógico e estruturante da condição inconsciente, desesperando em traduzir a falta de contato com uma outra linguagem da substância incestuosa impossível (a noção de trauma se amplia). Nem um nem outro anula que ambas as maneiras dependam de um tipo de nucleação determinante por uma idéia de matriz, de uma origem de onde vem o mal.

De Freud partem as duas tendências. Mesmo sem poder desenvolver, indico um aspecto capital que mostra onde a questão do "amor" acaba pensada por um esquema de matriz (estamos no caminho do Édipo, vertente masculina). "Uma observação direta e também a iluminação psicanalítica dos restos infantis feita 


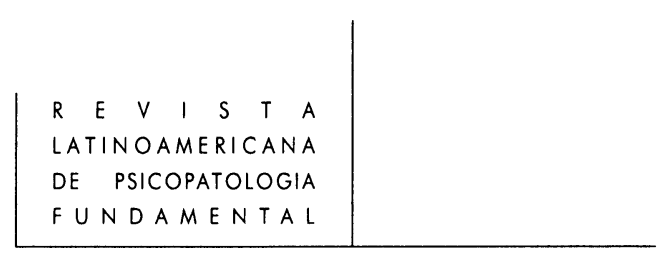

depois não deixam dúvida alguma sobre a confluência dos sentimentos ternos e invejosos e dos desígnios sexuais, e demonstram a maneira radical pela qual o menino faz da pessoa amada o objeto de todas as suas tendências sexuais, ainda não centradas corretamente".

Ora, ainda que seja num contexto bem delimitado (menino e não bebê), o problema de uma nucleação está presente. O que cabe é saber se tudo o que se centrou, e ainda por cima corretamente, duplo centramento, impede que tendências sexuais possam não seguir um curso - parece - tão determinado quantitativamente. Primeiro, pela regularidade média de distribuição da marcação sexual anatômica. Segundo, pela regularidade majoritária das adesões sexuais. É por aí que o acaso precisa ser pensado. Como aparição de algo em aberto. O acaso do encaixe, lá do Maturana. $\mathrm{O}$ acaso do encontro em estado de recalque. $\mathrm{O}$ acaso do unheimlich. E até onde vai esse unheimlich? O que Lacan fez foi construir um centro em aberto, potente como o poder simbólico e sua deriva. Neste sentido, sua crítica à "relação de objeto", indo rápido, procura resguardar a chance de que a cultura materna acabe por dominar a potência inventiva do significante como prova de uma determinação radicalmente não-biológica. Embora Lacan tenha dito o que disse de Artaud, o fato é que ele respeitava por dentro os processos da estranheza. A questão é saber se as pulsões ainda não-inibidas (serão elas pensáveis?) conseguem "sobreviver" à carga de cuidados e de orientação. Quando se percebe que os indivíduos perpassam os coletivos e viceversa, a pergunta que fica é: quando um encontro de amor de fato o é a ponto de abrir um processo de "palavra plena"? É aí que a questão do amor em Lacan costeia a da arte, e abre com isso o espaço experimental das curas com os processos de verdade dentro da condição do ser falante.

Assim, acredito que o enorme incômodo que Lacan causou se deveu a que pôs a ênfase não numa sabedoria - de outro modo absolutamente necessária de cunho fantasístico materno, mas no lado da função nomeadora e da força do ato atingível diante de um impossível absoluto, sendo a resistência tudo o que satisfaz dificultando o acesso ao essencial: o impossível. Toda a questão está em como ser fiel ao que não se realiza. É nisso que se destaca a vocação ética dessa conformação antropológica. Neste momento, apesar da enorme sofisticação algébrica e topológica, a ética funcionaria como correspondente funcional na cultura daquele horizonte de socialização que movimenta a permanência complexificada da própria vida. Se semantização do Outro pela vertente etológica coloca o horizonte da socialização possível como medida do "amor", a concepção de Lacan procura semantizar o Outro pelo regime transcendental de uma invenção amatória: o "amor cortês", por exemplo. A Dama impossível que faz exército de amantes, que, por provas de pureza (leia-se: por análise), em cruzada pelo mundo, figura o tragicômico da ação verdadeira. Se o vínculo social adquire forma 


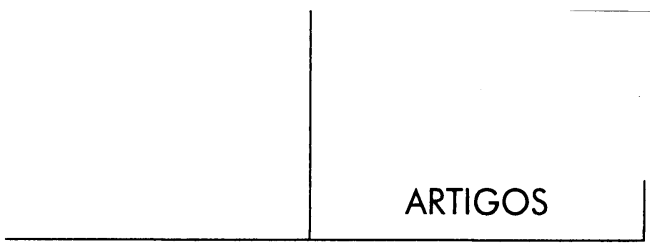

determinada por um discurso como o científico, se a psicanálise, no que trata do "amor", não se compatibiliza inteiramente com ser científica, a questão que fica em aberto é a de saber o tipo de vínculo que decorreria da ação analítica. $O$ que não pode se remedeia; fala-se de "amor", a relação sexual é sempre um logro, não há, e o que afeta (é uma concepção de afeto) é esse girar em torno sem pegar. Amar, para além de declarar o amor, é fazer movimentar o encontro. Amar e desejar não são a mesma coisa. Mas é claro que o esquema que pensa o encontro se confunde com o da conquista de um objeto desejado. O que move o desejo é o eletivo pulsional antigo. $O$ desejo é sempre convergente, o amor não; o amor é no mínimo disjunto. De novo, é aí que é importante conceber o acaso de um encontro com o objeto do desejo e o acaso no encontro do amor. Isso não significa que se anulem, só que são diferentes. De acordo com as fórmulas quânticas, o embevecimento no amor seria masculino, já que fica siderado pelo que foi o encontro, enquanto o trabalho do amor, a coerência da fidelidade, das provas de amor, seriam feminino. "Por estar na relação sexual, em relação ao que é possível dizer-se do inconsciente, radicalmente Outro, a mulher é o que tem relação com esse Outro" (p. 75). É claro que esse "radicalmente Outro" desobjetualiza o esquema pulsão-desejo, mas amarra a pulsão ao significante. É aí que precisaremos reconceituar o afeto. Talvez não baste mais um afeto concebido em função do esbarro com o impossível. O fogo queima e isso é um grau do afeto, mas não todo modo de afeto. Existe também a sintonia. E sintonia não é encaixe nem efeito de memória. Precisaremos desenvolver melhor o que é sintônico no amor assim referenciado.

\section{IV}

Badiou, filósofo, faz uma observação curiosa a respeito da ambigüidade da concepção de amor elaborada por Lacan. O autor descarta três definições do amor, no seu interesse de pensar os procedimentos genéricos de uma verdade, sendo o amor definível como um deles. A primeira conceberia o amor em função da supressão do múltiplo (Tristão e Isolda de Wagner). A segunda conceberia o amor como uma transcendentalização do outro. A terceira cito inteira:

Recusa da concepção "super-estrutural”, ou ilusória, do amor, cara à tradição pessimista dos moralistas franceses. Entendo, com isso, a concepção que enuncia que o amor é apenas o semblante ornamental por onde passa o real do sexo. Ou que desejo e inveja sexual são o fundo do amor. Lacan costeia por vezes essa idéia, quando diz, por exemplo, que o amor é o que remedeia a falha de relação sexual. Mas ele diz também o contrário, quando concede ao amor uma vocação ontológica, a da "abordagem do ser". É que o amor, creio nisso, não remedeia nada. Ele suplementa, o que é bem diferente. Ele só é 


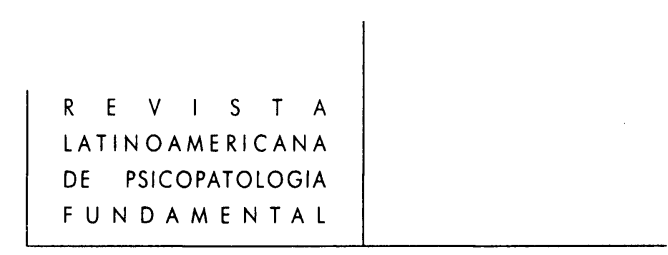

fracasso sob a suposição falaciosa de que é uma relação. Mas ele não é isso. É uma produção de verdade. Verdade sobre o quê? Sobre o fato de que o Dois, não apenas o Um, opera na situação. (p. 256)

A concepção de Badiou como produção de verdade nos leva a considerar o encontro na situação, o Dois sendo movido por um Eros fora da dialética do outro. A análise interpretativa que faz da obra de Samuel Beckett torna exemplar tais máximos de insistência na disjunção. Nenhuma psicologia. Somente a consideração prática do amor como estados máximos de abordagem do que é expectante e vive sob o signo do vir a ser.

Tudo indica a pertinência da abordagem feita por Badiou, sobretudo se lermos o livro de André Bernold, que ilumina pedaços do cotidiano de Beckett nos últimos dez anos de sua vida, trazendo enorme consistência ao trabalho de Badiou. Badiou procura mostrar, com muito rigor, um amor num campo de interseções, como uma forma substantiva de viver. No entanto, como a forma axiomática se encarnaria? Como se chega a esse Dois em aberto? Seria ele recursivo? Nada em princípio o obriga a ser assim, exceto se exclusivamente deriva da lógica do vivo. A tendência é que o esquema viático acabe imperando, reduzindo o pensamento a uma adequação moral. O que tinha caráter de revelação acabando por virar obrigação. Não custa para que o Dois, sem síntese possível, se torne um preceito amoroso para se amar verdadeiramente. A dificuldade de tudo isso, no entanto, entre a perspectiva do filósofo e o seu trabalho de fazer filosofia e a posição clínica, é que o Dois filosófico não é o mesmo que o Dois da cena psicanalítica. A psicanálise não consegue esquecer toda a extensão rigorosamente íntima do que motiva, por exemplo, acontecer estar disjunto como forma de amar. O livro de Anzieu sobre a psicanálise, Beckett e Bion ajuda a perceber isso, o lado íntimo doentio, o trabalho da saúde possível, a "produção de verdade", como superação e cura. Há coisas que, embora categorizáveis, acontecem e se realizam não-categorialmente.

Numa via analítica, a percepção de um experimentalismo amatório decorrente do próprio lidar com a transferência e do que se alcança de um encontro mais que estranho, posto que cinde em vez de juntar, ao mesmo tempo que se acha juntado pelo encontro, certamente é importante. Sob que condições é o amor um processo de fato experimental? Ou a produção de verdade é a revivência de um estado já visto? É aí que precisamos nos perguntar se os conceitos analíticos não trazem uma referência que ainda precisaremos reavaliar. As pulsões, representações e afetos ficam referidos a que condição ou condições? O estado de não terem sido conectados os eliminaria de acordarem para vida? Acho que está na hora de nos perguntarmos o que sabemos de tudo isso. Precisamos nos perguntar em que medida o celibatário será a figura por excelência que encarnaria o núcleo de um amor condição genérica? Mas, para o analista, como não levar em conta a dimensão cognoscente do outro através do qual algo se abala e da situa- 


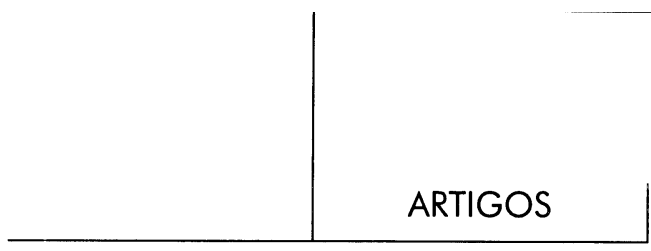

ção em que se traça um tempo íntimo não-vinculado à reprodução do tempo social?

Bibliografia

AnZIEU, Didier. Beckett et le psychanaliste. Paris, Mentha Archimbaud, 1992.

BADIou, Alain. "Qu'est-ce que l'amour?" e "L'écriture du générique: Samuel Beckett", in Conditions. Paris, Seuil, 1992.

Bernold, André. L'amitié de Bechett. 1979-1989. Paris, Hermann, éditeurs des sciences et des arts, 1992.

FREUD, Sigmund. "Sobre un tipo particular de elección de objeto en el hombre (Contribuciones a la psicología del amor, I)"; "Sobre la más generalizada degradación de la vida amorosa (Contribuciones a la psicología del amor, II)" e "El tabú de la virginıdad (Contribuciones a la psicología del amor, III)", in Obras Completas, vol.XI. Buenos Aires, Amorrortu, 1994.

"Sobre la dinámica de la transferencia" e "Puntualizaciones sobre el amor de transferencia", in Obras Completas, vol. XII. Buenos Aires, Amorrortu, 1994.

"Psicología de las massas y análisis del yo", in Obras Completas, vol. XVIII. Buenos Aires, Amorrortu, 1994.

LaCAN, Jacques. "Une lettre d'âmour", in Le Séminaire. Livre XX. Encore. Texte établi par Jacques-Alain Miller. Paris, Seuil, 1975.

"Séminaire du 16 novembre 1976" (L'insu que sait de l'une bevue s'aile a mourre). (Texte établi par Jacques-Alain Miller). Ornicar? (12/13). Bulletin périodique du Champ freudien. Paria, Lyse, décembre 1977.

Maturana, Humberto. "Reflexões sobre o amor", in A ontologia da realidade. (Texto organizado por Cristina Magro et allii). Belo Horizonte, Editora UFMG, 1997.

\section{Resumos}

Este artículo busca cuestionar ciertas dificultades implicadas en el uso nopensado del término "amor" en psicoanálisis. Partiendo de la identificación de semánticas que caracterizam los significados de la palavra "amor" se pregunta: “ ¿Son estes los significados que componen y dan norte a las coordenadas de la comprensión psicoanalítica?" Lo que se busca mostrar es como la aceptación de la hipótesis del inconsciente determinaría el eje semántico y conceptual con el cual se aborda todo lo que se designa como "amor".

De manera bien sintética el autor examina que factores caracterizaran el determinismo del amor y de los amores. Esboza um cuadro en donde es posible ubicar como el pensamiento psicoanalítico entiende el origen de muchos de los sufrimientos que de él derivan. Recoloca y reconsidera la enorme importancia de que se conciba el encontro de "amor". De este modo, el trabajo es un derrotero articulado para 


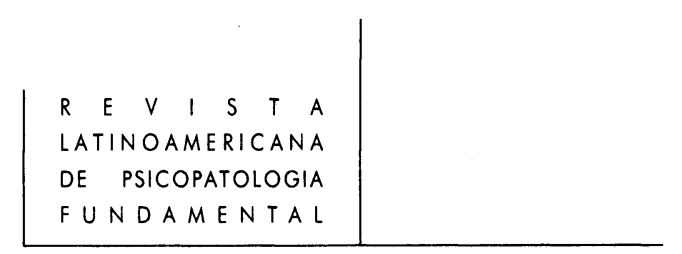

que se precise: (1) la necesidad de repensar las implicaciones de sentido de las transferencias y de los tipos distintos de amor en la clínica psicoanalitica; (2) la naturaleza de los fenómenos amorosos en la medida en que se acepta la hipótesis de un inconsciente. La cuestión que queda en suspensión puede ser formulada así: “ ¿En qué medida todos los amores se conducirán tal como está previsto por las metapsicologias más dominantes en el campo psicoanalítico?”

Ce travail vient questionner certaines difficultés impliquées par l'usage irréfléchi du terme "amour" dans la psychanalyse. L'identification des sémantiques caractérisant les significations du mot "amour" nous amène à nous demander: "S'agit-il bien des significations qui composent et orientent les coordonnées de la compréhension psychanalytique?" L'on cherche à montrer combien l'acceptation de l'hypothèse d'un inconscient détermine l'axe sémantique et conceptuel servant à aborder tout ce qui est désigné sous le nom d' "amour".

D'une manière très synthétique, l'auteur examine les facteurs caractérisant le déterminisme de l'anour sous toutes ses formes. Il dessine un cadre permettant de situer comment la pensée psychanalytique comprend l'origine des nombreuses souffrances qu'elles entraînent. Il reprend et reévalue l'importance capitale de concevoir la découverte de l' "amour". Ce travail est donc un scénario articulé pour montrer: (I) le besoin de reconsidérer les implications des significations des transferts et des amours dans la clinique psychanalytique; (2) la nature des phénomènes de l'amour si l'on accepte l'hypohèse d'un inconscient. Une question reste alors en suspens: "Jusqu'à quel point tous ces amours se comporteraient-ils comme le prévoient les métapsychologies dominantes dans le champ psychanalytique?"

This work considers some of the difficulties implied by an unconsidered use of the word "love" in psychoanalysis. Identifying the semantics that characterize the meanings of this word brings a question forth: "Are those the meanings that compose and orient the psychoanalytic comprehension standards?" This is intended to show how accepting the hypothesis of the unconscious determines the conceptual, semantic axis used to approach whatever may be labeled as "love".

In quite a synthetic way, the author examines the factors that characterize the determinism of love in all its forms. He draws a framework that allows us to determine how the psychoanalytical thought understands the origin of many a suffering they entail. He retrieves and reconsiders how decisive the conception of discovering "love" is. This work is thus a script articulated to highlight: (1) the necessity of reconsidering the implications of the meanings of both transferences and loves in the clinical psychoanalysis; (2) the nature of the love phenomena once the unconscious hypothesis is embraced. A question would still remain in the air: "To what extent would all loves behave as predicted by the chief psychoanalytic metapsychologies?". 